\title{
Europe compromises on GM crops
}

\author{
For more than a decade political stalemate has enforced a de facto ban on the exploitation of genetic \\ modification technologies by European agriculture. It is to be hoped that a recent compromise by the \\ European Parliament will allow reasoned decision-making to proceed.
}

One of the aims of Nature Plants will be to better represent the importance of advances in our fundamental understanding of the plant kingdom alongside discussion of the technological innovations that follow from that knowledge. But no benefits can be reaped from a scientific advance without the political will to see it exploited. In this context the compromise recently reached by the European Parliament over genetically modified crop legislation should be viewed with some relief.

Europe has been in a paradoxical position with regard to plant science for some time. Its scientists are at the forefront of technological advances, including the creation of transgenic crop varieties engineered for resistance to specific diseases, enhanced nutritional properties and other desirable traits. Yet in 15 years only 2 GM crops have been licensed to be grown commercially in the European Union. The first of these was BASF' 'Amflora' potato, engineered to produce higher quality amylopectin, a valuable raw material for industries such as papermaking. The Amflora potato was approved for commercialization by the European Commission (EC) in March 2010 but withdrawn from production by BASF in January 2012. At the same time, BASF moved its main research centre for GM crops from Germany to the USA stating that "in the mid-term, BASF does not see any opportunities for the commercial cultivation of GM plants in Europe". The second is a variety of maize developed by Monsanto: MON810. This was made resistant to a number of insect herbivores, including the European corn borer, through the introduction of a toxin-encoding gene from the bacterium Bacillus thuringiensis. In 2013, just under 150,000 hectares were cultivated, mostly in Spain. In contrast, Europe imported around 30 million tons of GM produce in 2012, mainly soya for animal feed.

The lack of success of GM crops in Europe has arisen in part because of negative public opinion. A 2010 survey carried out as part of the EC's Eurobarometer program found that $58 \%$ of Europeans disagreed with the statement 'GMO food is safe for future generations', with only $21 \%$ agreeing. Compared with the challenges facing agriculture in Africa (see Comment by P. A. Sanchez in this issue), Europe's 'local difficulties' may seem somewhat parochial. However, prominent researchers fear that without an avenue to derive practical benefits from their discoveries a strong history in plant biology will wither. Meanwhile strong opposition to GM technologies led to the dismissal in November of Anne Glover, the Chief Scientific Advisor to the President of the EC.

Former EC President, José Manuel Barroso, created the post of Chief Scientific Advisor in 2012 and appointed Glover as its first incumbent to "provide independent expert advice on any aspect of science, technology and innovation". Her remit covered all aspects of science but her remarks on GM organisms were very clear. At a conference of the European Network on Soil Awareness in September 2013 she said, "No other foodstuff has been so thoroughly investigated as GM. No scientist will ever say something is 100\% safe but I am $99.99 \%$ certain from the scientific evidence that there are no health issues with food produced from GM crops. Just about every scientist I know supports this view. Opposition to GM, and the benefits it can bring, is a form of madness I don't understand." Soon after Jean-Claude Juncker, the former Prime Minister of Luxembourg, succeeded Barroso as EC President in November 2014 he was presented with a letter from environmental pressure groups saying that Glover had "presented one-sided, partial opinions in the debate on the use of GM organisms in agriculture, repeatedly claiming that there was a scientific consensus about their safety". By 13 November Juncker had both dispensed with Glover's services and with the role of Chief Scientific Advisor.

Leading plant scientists working in Europe greeted the arrival of Juncker with the publication of an open letter calling on the "Decision Makers of Europe" to back research into plant biotechnology. Along with the "prompt authorization of GM plant varieties" they asked that European authorities "ensure that approved and safe field experiments with transgenic plants are made possible" and that those who disrupt such trials be "prosecuted and held accountable for scientific and financial damage". The letter was signed by 21 scientists, co-ordinated by Stefan Jansson of Umeå University, Sweden, who pointed out that this was not "a list of scientists with links to industry who some might say 'would say that anyway" ", but members of the 30 most cited researchers in plant science in Europe. "Politicians that choose to ignore this message cannot in the future say that they take science seriously", he said.

Progress on GM crops in Europe has been stalled for at least four years over the principle that every member state of the EU must honour EC approvals of GM crops, putting the Commission into conflict with countries such as France, Austria and Luxembourg, who oppose any cultivation of transgenic crops. However, in December 2014 this deadlock was broken by the European Parliament agreeing to allow individual states to ban crops despite them being approved for use by the EC, a decision hailed as a success by both sides. The European Commissioner for Health and Food Safety, Vytenis Andriukaitis, feels that it will "give the democratically elected governments at least the same weight as scientific advice" while Jonathan Jones of the Sainsbury Laboratory in Norwich, UK and a signatory of Jansson's letter, told Nature (http://doi.org/xmq) that "those who don't want to ignore the science can go ahead and use the science more easily". However, there are opponents, like Bart Staes, a Belgian Green Party Member of the European Parliament, who is concerned that the deal "risks being a Trojan horse ... for easing EU GMO authorisations".

We cannot know what the effect of this decision could have been if made even four years ago. Now new techniques such as genome editing (see Comment by $\mathrm{H}$. D. Jones in this issue), whose need to be governed by the same legislation as transgenic technologies is unclear, may make it irrelevant. It will also do nothing to address the difficulties of safely performing field trials, highlighted in the letter from Jansson and colleagues. However in the current political climate any step that promotes, even partially, evidence-based decision-making in Europe deserves praise. 